\title{
The Hub model: It's time for an independent summative evaluation
}

\author{
Cal Corley* and Gary Teare ${ }^{\dagger}$
}

\begin{abstract}
Over the past decade, governments and the non-profit, private, academic, and philanthropic sectors have begun thinking differently about how human and social services are organized and delivered. Across Canada, a range of integrated health and social care practices are being developed, adapted, and implemented to meet local needs. The Hub (or Situation Table as it is more commonly known in Ontario) model is one such approach. The Hub model is a multi-sector, collaborative, risk-driven intervention that mobilizes multi-sectoral human services for the purpose of rapid risk mitigation focused on the immediate needs of persons experiencing acutely elevated risk of harmful safety or well-being outcomes. Over the past eight years, the model has been adopted in over 115 communities across Canada.

While the model has benefited from developmental and formative evaluations, it is now timely to undertake a systematic multi-site evaluation of the generalizable impacts (e.g., clients, system, costs) and lessons learned about what works, in which context, and why. This body of work will serve to inform policymakers, funders, practitioners and others as to the way forward with the Hub model. The Community Safety Knowledge Alliance (CSKA) is moving forward on a plan to see such independent evaluation undertaken.
\end{abstract}

Key Words Summative evaluation; Hub model; situation table; formative evaluation; community safety and well-being; impact outcomes.

Journal of CSWB. 2019 April;4(1):10-12

www.journalcswb.ca

The Hub model (or Situation Table as it is more commonly known in Ontario) is a multi-sector, collaborative, risk-driven intervention approach to mobilizing multi-sectoral human services for the purpose of rapid risk mitigation focused on the immediate needs of clients experiencing acutely elevated risk of deleterious safety or well-being outcomes. This model of practice, which has undergone rapid, widespread adoption, comprises a disciplined process of risk detection, sharing of limited/need-to-know information, and deployment of rapid, risk-mitigating intervention(s). Other individual or multi-sector service approaches can be used to address client needs with lower or chronic risks or to address broader systemic issues.

The Hub model makes practical sense on a number of levels. It has strong intuitive and anecdotal appeal and, in less than eight years, has been adopted by over 115 communities across Canada as well as a few in the Northeast United States. And at first blush, what's not to like? A growing number of police and other community leaders are realizing that the more traditional and siloed approaches of the past are largely inadequate. More than one professional has proclaimed something to the effect that, My biggest ah-ha moments have not always been about the crises averted, but rather that I have worked with some of these clients for many years and it has only been since we adopted the Hub approach that I have a fuller understanding of the individual's situation. That wasn't possible when we operated in silos.

Another positive aspect in our view is that the significant uptake of the Hub model since its inception has not stemmed from government efforts to scale up or expand. Rather, its replication has been driven by local human service professionals who are seeking pragmatic inter-disciplinary opportunities to improve access to help for at-risk clients before harm occurs.

Informing many communities throughout the replication process over the past eight years has been conceptual understandings laid out by developmental evaluators (Nilson, 2014) and key lessons captured by formative evaluators (Babayan, Landry-Thompson, \& Stevens, 2015; Brown \& Newberry, 2015; Lansdowne Consulting Group, 2016; Litchmore, 2014; Ng \& Nerad, 2015; Nilson, 2014; Nilson 2016a; Nilson 2016b). As the Hub model continues to gain momentum, it is important to continue to build capacity and interest for further evaluation. Since the model itself is designed to merely mobilize services in situations of acutely elevated risk, building specific enough 
indicators to measure changes in risk will become increasingly important.

We advocate that, notwithstanding a number of formative evaluations undertaken to date and the inherent benefits to be gained by conducting more of those, it is also now time for an independent summative evaluation of the Hub model.

\section{The Hub Model and the Field of Community Safety and Well-Being}

Over the past decade, governments and the non-profit, private, academic, and philanthropic sectors have begun thinking differently about how human and social services are organized and delivered. Across Canada, a range of integrated health and social care practices are being developed, adapted, and implemented to meet local needs as these sectors coalesce to help solve complex social issues and improve community safety and well-being (CSWB). These innovations include collaborative risk-driven intervention (CRDI), multi-sector coordinated support, systems-focused solution building, bi-sector response teams, and problem-solving courts (Nilson, 2018).

Under a framework of CSWB, these different collaborative social innovation models can help one another improve and strengthen. Moving forward, we should explore opportunities for shared measurement, outcome tracking, and new indicator development. Many of the measurement indicators we are accustomed to using in our various silos (e.g., crime reduction, school truancy, employment) may not be relevant in a multi-sector collaborative context. Under a consolidated CSWB framework, we can begin examining outcomes for what they are-not for what our traditional siloed disciplines tell us they should be! By building capacity for measuring the impact of the Hub Model, multi-sector coordinated support, systemic solution building, bi-sector response teams, or problem-solving courts, etc., we will enhance our capacities to improve community safety outcomes.

\section{Current State of the Evidence Base Concerning the Hub Model}

Several of the current Hubs/Situation Tables have undertaken some level of evaluation of their implementation of the approach, and some work has been done to consolidate learnings from these evaluations and standardize key evaluation metrics for CRDI and related CSWB initiatives (e.g., Russell \& Taylor, 2014; Nilson, 2015; Nilson, 2017).

Overall, most evaluations have been formative in nature-assessments of the development and application of the CRDI processes. This has largely been due to the importance of establishing consistent implementation of a model that is required for proper impact evaluation. Methodologies of these formative evaluations have included qualitative feedback from representatives of participating service agencies; output data on service/intervention activity; pre/post service demand analysis; and some limited assessments of client and system impacts. Most evaluations have been conducted by evaluators contracted by local organizations who are part of a Hub/Situation Table (Brown \& Newberry, 2015; Lansdowne Consulting Group, 2016; Ng \& Nerad, 2015; Nilson, 2016b).

The Hub model has demonstrated utility in establishing multi-sectoral collaborations in human services, with a sharp focus on urgent client issues. Various impacts/effects of the approach have been reported from past evaluations, including quicker access to services (Nilson, 2014), improved crosssectoral communication and working relationships $(\mathrm{Ng} \&$ Nerad, 2015), and self-reports by workers and clients of more effective, supportive services (Babayan, Landry-Thompson, \& Stevens, 2015; Brown \& Newberry, 2015; Lansdowne Consulting Group, 2016; Nilson, 2016b). Collectively, this evaluation experience has strengthened fidelity to the model, improved efficiency of Hub/Situation Tables, and informed community stakeholders of the short-term outcomes of collaborative riskdriven intervention.

However, evaluations to date have not been sufficiently resourced and designed to ensure rigorous assessment of impacts. That goes for both clients and the human services system. Past efforts-including a January 2017 national symposium held in Toronto-to facilitate broad dialogue regarding further assessment of the Hub model have revealed considerable interest and opportunity among evaluators, policy, and practitioner stakeholders to explore such options (Nilson, 2017).

\section{The Need to Strengthen the Evidence Base Concerning the Hub Model}

As noted above, the widespread adoption of the Hub model suggests it is an approach to multi-sectoral human services with intuitive and anecdotal appeal. However, like any intervention, the model entails both costs and benefits/effects. The suitability of sustained commitment to, and further spread of, the approach can only be assessed based on rigorous impact evaluation. Further, a more systematic evaluation of the Hub model at this juncture is important to continuous learning, improvement, and standardization of the model itself.

Why now? Until now, the measurement community lacked strong enough samples of Hub/Situation Tables with sufficient years of experience applying the model to allow for proper impact measurement. However, with improvements in the model's fidelity at local levels, together with lessons learned from past formative and developmental evaluations, we believe that the time is now right for a summative evaluation of the Hub model.

A multi-site evaluation of the generalizable impacts (e.g., client, system, costs) and lessons learned about what works in which contexts, and why, will go a long way to informing policymakers, funders, practitioners, and other stakeholders as to the way forward with the model. Increasingly, governments and other funders want to invest in social and human service interventions that measurably contribute to improved outcomes and have impact.

The widespread adoption and sustained use of the Hub model in numerous jurisdictions suggests that the approach has practical merit. Now it is time for an independent summative evaluation to determine the model's impacts on those it strives to help. To that end, the Community Safety Knowledge Alliance is now socializing a three-phase evaluation approach with potential funders and key stakeholders.

Phase 1 will centre on a review of the existing body of relevant evaluative work and will produce a consolidated knowledge base that will be maintained and widely accessible for other research. 
Phase 2 will assess the evaluability of current Hubs/ Situation Tables to determine which are suitable for a rigorous summative evaluation. Such criteria as model fidelity, organizational maturity, sufficient client flowthrough, and of course, local interest in participating in an evaluation will be considered.

- Phase 3 will entail a multi-site, multi-jurisdiction independent evaluation. Through a request for proposals, an evaluation team will be selected to design and implement a rigorous evaluation of impacts on providers, clients, and human services systems and to elucidate important elements of context and the mechanisms that drive the impacts.

Work towards Phases 1 and 2 has already begun. Once the Community Safety Knowledge Alliance (CSKA) secures funding support for Phase 3, a call for expressions of interest in taking on this important evaluation will go out to the evaluation and research community.

\section{CONFLICT OF INTEREST DISCLOSURES}

The authors state that there are no conflicts of interest. Cal Corley is the Chief Executive Officer of the Community Safety Knowledge Alliance (CSKA). Dr. Gary Teare is a Senior Scientist with Alberta Health Services. He is a former member of the CSKA Board of Directors.

\section{AUTHOR AFFILIATIONS}

* Community Safety Knowledge Alliance, Saskatoon, SK; ${ }^{\dagger}$ Alberta Cancer Prevention Legacy Fund, Alberta Health Services, Edmonton, $\mathrm{AB}$.

\section{REFERENCES}

Babayan, A., Landry-Thompson, T., \& Stevens, A. (2015). Evaluation of the Brant community response team initiative: Six-month report. Brantford, ON: Brant County Health Unit.

Brown, J., \& Newberry, J. (2015). An evaluation of the connectivity situation tables in Waterloo Region. Evaluation report submitted to
Waterloo Region Connectivity Partnership. Guelph, ON: Taylor Newberry Consulting.

Lansdowne Consulting Group. (2016). Multiagency early risk intervention tables: Pilot project review. Ottawa, ON: The Lansdowne Consulting Group.

Litchmore, R. (2014). Preliminary report on the progress of the Guelph situation table. Internal Report Provided to Guelph Situation Table. Guelph, ON: University of Guelph.

Ng, S., \& Nerad, S. (2015). Evaluation of the FOCUS Rexdale pilot project. Delivered to the City of Toronto and Toronto Police Service. Toronto, ON: Vision and Results Inc. and SN Management.

Nilson, C. (2014). Risk-driven collaborative intervention: A preliminary impact assessment of community mobilization Prince Albert's hub model. Saskatoon, SK: Centre for Forensic Behavioural Science and Justice Studies - University of Saskatchewan.

Nilson, C. (2015). Measuring change: A framework to support evaluation of collaborative risk-driven community safety and well-being in Ontario. Delivered to the Ontario Working Group on Collaborative Risk-Driven Community Safety. Prince Albert, SK: Living Skies Centre for Social Inquiry.

Nilson, C. (2016a). Collaborative risk-driven intervention: A study of Samson Cree Nation's application of the Hub model. Ottawa, ON: Public Safety Canada.

Nilson, C. (2016b). Collaborative risk-driven intervention evaluation brief: A preliminary analysis of discussion subject and table discussant satisfaction, understanding and perceived impact of Collaborate Barrie's efforts to mitigate acutely-elevated risk. Toronto, ON: Global Network for Community Safety.

Nilson, C. (2017). Collaborative risk-driven intervention: An interactive national dialogue on research, evaluation and analysis of the Hub/ Situation Table and related CSWB models (Summary of dialogue: January 24-25, 2017, Toronto, ONI. Saskatoon, SK: Community Safety Knowledge Alliance.

Nilson, C. (2018). Community safety and wellbeing: Concept, practice and alignment. Saskatoon, SK: Community Safety Knowledge Alliance.

Russell, H., \& Taylor, N. (2014). New directions in community safety: Performance measures for community safety and well-being. Toronto, ON: Ontario Working Group on Collaborative, Risk-Driven Community Safety/Ontario Association of Chiefs of Police. 